\title{
HISTÓRIA DO ENSINO SECUNDÁRIO NO BRASIL: O CAMINHO PARA AS FONTES ${ }^{1}$
}

\author{
THE HISTORY OF SECONDARY SCHOOL IN BRAZIL: THE WAY \\ TOWARDS THE SOURCES
}

\section{LA HISTORIA DE LA EDUCACIÓN SECUNDARIA EN BRASIL: EL CAMINO HACIA LAS FUENTES}

\begin{abstract}
Eurize Caldas Pessanha
Universidade da Grande Dourados (UFGD), Professora do Programa de Pós-Graduação em Educação da Faculdade de Educação; Coordenadora do Grupo de Pesquisa Observatório de Cultura Escolar (CNPq)
\end{abstract}

\section{Wanderlice da Silva Assis ${ }^{3}$}

Universidade Federal de Mato Grosso do Sul, Bibliotecária da Coordenadoria da Biblioteca Central

\section{Stella Sanches de Oliveira Silva ${ }^{44}$}

Universidade Federal de Mato Grosso do Sul, Professora Adjunta da Faculdade de Educação

Resumo: Neste artigo mapeiam-se fontes da história do ensino secundário no Brasil; ele é resultado da primeira etapa de um projeto de pesquisa sobre esse nível de ensino. Trata-se de uma pesquisa bibliográfico-documental sobre teses e dissertações dos programas de pós-graduação e a legislação pertinente. As fontes foram categorizadas como documentais, arqueológicas, impressas, iconográficas, orais, biográficas e audiovisuais. Constatou-se que as primeiras instituições secundárias resultaram de mobilização de grupos influentes de cada cidade e da participação do poder municipal na sua manutenção. Caminhos foram indicados, mas é necessário ampliar o mape-

\footnotetext{
${ }^{1}$ Este trabalho é resultado de pesquisa financiada pelo CNPq e é uma versão modificada do trabalho publicado nos Anais do XI Congresso Luso-Brasileiro de História da Educação (Porto, Portugal) em junho 2016.

${ }^{2}$ Pós-doutora, como bolsista da Capes, no Departamento de Curriculum and Instruction na University of Wisconsin (Madison), em 1999, e, em 2010, concluiu o estágio de pós-doutorado na Texas A\&M University em College Station, Texas, Estados Unidos; Doutora em Educação pela Universidade de São Paulo.

${ }^{3}$ Doutora e Mestre em Educação pela Universidade Federal de Mato Grosso do Sul.

${ }^{4}$ Pós-doutora em Educação pela Universidade Federal de Mato Grosso do Sul, com bolsa PNPD/Capes; Doutora em Educação, com pesquisa em História da Educação, pela Universidade Federal de Mato Grosso do Sul.
} 
amento, problematizar as fontes primárias e secundárias e levantar mais hipóteses sobre como se realizou a implantação e a expansão do ensino secundário no Brasil.

Palavras-chave: História da Educação. Ensino secundário. Fontes.

\begin{abstract}
The article maps historical sources of the secondary school in Brazil and is the result of the first part of a research project regarding this teaching level. It is a bibliographic-documentary research about thesis and dissertations of graduate programs and relevant legislation. The fonts were categorized as: documentary, archeological, printed, iconographic, oral, biographical and audiovisual. It was observed that the first secondary institutions were the result of the mobilization of influent groups from each city and the participation of the municipal power on their maintenance. Paths were indicated, but it is necessary to amplify the mapping, problematize primary and secondary sources and raise further hypotheses about how the implementation and expansion of the secondary school in Brazil happened.
\end{abstract}

Keywords: History of education. Secondary education. Sources.

Resumen: El artigo traza las fuentes de la historia de la educación secundaria en Brasil y es el resultado de la primera etapa de un proyecto de investigación sobre este nivel de educación. Se trata de una investigación bibliográfica y documental sobre las tesis y disertaciones de los programas de postgrado y de la legislación pertinente. Las fuentes se clasificaron como: documental, arqueológico, impreso, iconográfico, oral, biográfica y audiovisual. Se encontró que las primeras instituciones secundarias resultaran de la movilización de los grupos influyentes en cada ciudad y de la participación del poder municipal en su mantenimiento. Caminos fueron indicados, pero es necesario ampliar el mapeo, problematizar las fuentes primarias y secundarias, y recaudar más hipótesis sobre cómo se llevó a cabo la instalación y la expansión de la educación secundaria en Brasil.

Palabras clave: Historia de la Educación. Educación secundaria. Fuentes.

\title{
1 INTRODUÇÃO
}

O uso de fontes é fundamental para a produção e a sistematização do conhecimento histórico, pois testemunham, fundamentam e embasam a pesquisa histórica. Como nos lembra Saviani (2004), esses vestígios e indícios acumulados, guardados e preservados são indispensáveis para a compreensão dos processos históricos. 
Nessa direção, neste artigo focaliza-se a busca por fontes que possam se tornar base para a escrita da história do Ensino Secundário no Brasil, no período de 1837 a 1971.

Pesquisas que viemos realizando há algum tempo sobre a história do Ensino Secundário no Brasil têm nos colocado diante de questões teórico-metodológicas que parecem ter sua origem na própria ambiguidade do termo "secundário" que adquiriu sentidos diferenciados em cada momento da história da educação no Brasil. Essa diferenciação de sentidos fez com que, na historiografia desse nível de ensino, termos de sentidos diferentes em cada momento histórico, como educação secundária, ensino secundário e ensino médio, sejam frequentemente usados como sinônimos, embora com a conotação comum de nível intermediário de escolarização.

No Brasil, a etapa média de escolarização voltada à juventude, que permitia o acesso aos cursos superiores, recebeu várias denominações ao longo de sua história: instrução secundária, ensino secundário, educação secundária, curso ginasial, curso secundário fundamental. As instituições de ensino secundário receberam, em cada período, denominações diferentes: Liceu, Colégio e Ginásio. O nome utilizado para o ensino secundário pela Reforma Benjamin Constant, de 1890, foi curso médio; em 1901, a nova reforma educacional, Epitácio Pessoa, denominou ensino secundário; a reforma posterior, Rivadávia, de 1911, deu o nome de curso fundamental; pela Reforma Maximiliano, de 1915, o ensino secundário passou a chamar-se curso gymnasial; em 1925, com a Reforma Rocha Vaz, voltou o nome ensino secundário.

A partir da década de 1930, as reformas dividiram esse nível de ensino em dois ciclos: em 1931, a Reforma Francisco Campos aprovou o $1^{\circ}$ ciclo como curso secundário fundamental e o $2^{\circ}$ curso como secundário complementar; em 1942, a Reforma Gustavo Capanema retomou o termo curso ginasial para o $1^{\circ}$ ciclo, enquanto o $2^{\circ}$ ciclo passou a ter duas opções para o jovem, curso clássico ou curso científico. Com a aprovação da primeira Lei de Diretrizes e Bases da Educação Brasileira, em 1961, os dois ciclos do ensino secundário passaram a denominar-se: ciclo ginasial e ciclo colegial, e, finalmente, em 1971, pela Lei n. 5.692, o ensino secundário foi reformulado com a denominação Ensino de $1^{\circ}$ e $2^{\circ}$ graus.

Como consequência dessa aparente ambiguidade, tornam-se difíceis e cruciais as decisões para a escrita da história desse nível de ensino: desde a periodização até o caminho para as fontes. Em sua acepção restrita, o marco inicial do ensino secundário no Brasil foi a transformação, em 1837, do antigo Seminário de São Joaquim no Imperial Collegio de Pedro II, inaugurado em março do ano seguinte. Inspirado no modelo francês de ensino secundário, esse estabelecimento tornou-se parâmetro para 
as demais instituições desse nível de ensino que somente conseguiam autorização para funcionar se demonstrassem alinhamento total ao modelo adotado.

A obediência a esses dispositivos legais parece ter garantido certa uniformidade às instituições de ensino secundário no País. Essa aparente uniformidade pode ter sido garantida também pelo sentido que esse nível de ensino foi assumindo para os grupos que se consideravam elite desde a segunda metade do século XX, consenso permeado de embates e contradições que se aprofundaram nas décadas de 1950 e 1960, acompanhando as transformações da sociedade brasileira no período (SOUZA, 2008).

Apesar disso, instituições diferentes em espaços e momentos históricos diversos apresentam peculiaridades que precisam ser analisadas se se pretende escrever a história desse nível de ensino no País, perpassada por debates e contradições. Muito provavelmente em virtude do sentido que os ginásios assumiram como aspiração de grupos sociais em busca de ascensão social pela educação, instituições de ensino secundário constituíram o foco de dissertações e teses dos programas de pós-graduação no Brasil, em várias áreas de conhecimento.

Para escrever a história dessas instituições, os pesquisadores começaram a localizar, separar, organizar e analisar uma multiplicidade de fontes, em sua maior parte, escondidas nos arquivos escolares como "papéis velhos" e não facilmente disponíveis para a comunidade acadêmica. Considerando que essas fontes constituem uma das bases para a escrita da história do ensino secundário, são apresentados neste trabalho resultados parciais dos caminhos percorridos pelos pesquisadores para escrever a história desse período no Brasil tendo como foco principal o caminho para as fontes.

O objetivo com este trabalho foi mapear as fontes já utilizadas para a escrita da história de instituições escolares do ensino secundário no Brasil, no período que vai de 1837 a 1971, em teses e dissertações, e propor caminhos que levem às fontes. Tomou-se como marco inicial a criação do Imperial Collegio de Pedro II, em 1837, não sendo incluídas as iniciativas e processos de educação, anteriores e simultâneos, que visavam preparar os estudantes para o acesso aos cursos superiores. Processos que, segundo Alves (2012), teriam desestimulado o funcionamento regular das instituições de Ensino Secundário. A Lei n. 5.692/1971, Lei de Diretrizes e Bases do $1^{\circ} \mathrm{e}$ $2^{\circ}$ Graus, que reestruturou o ensino incorporando os antigos níveis primário e secundário sob as denominações de Ensino de $1^{\circ}$ Grau e de $2^{\circ}$ Grau, constitui o marco final do período investigado. 


\section{DESENVOLVIMENTO}

Este trabalho se caracteriza como uma pesquisa bibliográfico-documental sobre as teses e dissertações em ensino secundário desenvolvidas nos programas de pós-graduação no Brasil e sobre a legislação pertinente. No caso das teses e dissertações, selecionaram-se produções não exclusivas da área da Educação, pois pesquisas com a temática voltada à História da Educação, neste caso específico, ensino secundário, têm lugar em diferentes áreas do conhecimento.

O ponto de partida da pesquisa foi a busca eletrônica das teses e dissertações sobre o ensino secundário, concretizada em agosto de 2015, na Biblioteca Digital Brasileira de Teses e Dissertações (BDTD), Banco de Teses da Capes, Catálogo Corrente da Biblioteca Nacional, Catálogo da Rede Pergamum - Tese e Dissertação - e, posteriormente, nos Catálogos Eletrônicos das Bibliotecas que não fazem parte dessa Rede, mas que, pelo título e assunto, remetiam àquelas com temáticas voltadas aos aspectos específicos de instituições escolares de ensino secundário. Produções sobre Formação de Professores (Ensino Normal, Magistério), Ensino Técnico, Comercial, Industrial, Militar e Agrícola não foram incluídas.

Como resultado da prospecção de fontes em teses e dissertações, foram localizadas 126 teses e dissertações que pesquisaram instituições de ensino secundário em 19 estados brasileiros, defendidas no período de 1967 a 2015.

De posse das teses e dissertações recuperadas, foi elaborada uma lista em ordem alfabética das denominações das diferentes instituições objeto de pesquisa. Cabe salientar que, para as instituições que tiveram ao longo de sua história várias denominações, foi atribuída a última.

Para essa análise, foram selecionados 16 trabalhos que representassem pelo menos dois estados de cada uma das cinco regiões do País. Assim, os trabalhos selecionados focalizam 17 cidades diferentes de 14 estados, a saber:

a) Região Norte (Porto Nacional/TO e Belém/PA): Dourado (2010) e França (1997);

b) Região Nordeste (Aracaju/SE, Teresina/PI, Salvador/BA e Goiana/PE): Guimarães (2012), Lima (2003), Sousa (2005) e Vasconcelos (2007);

c) Região Sul (Curitiba/PR, Itajaí/SC): Aksenen (2013) e Nicolau (2010);

d) Região Centro-Oeste (Cuiabá/MT, Campo Grande/MT e Corumbá/MS, 
Cidade de Goiás/GO e Jataí/GO): Barros (2006), Nolasco (2015), Oliveira (2014) e Pires (1997);

e) Região Sudeste (São Paulo/SP, Araraquara/SP, Rio de Janeiro (município da Corte)/RJ, Belo Horizonte/MG): Cabral (2002), Gentilini (2001), Perez (2006) e Rodrigues (2010).

As categorias (tipos) de fontes selecionadas para a análise dos dados coletados foram: documentais, arqueológicas, impressas, iconográficas, orais, biográficas e audiovisuais. As subcategorias surgiram no decorrer das análises, devidamente inseridas nas categorias de fontes pré-existentes. Considerando que todas as instituições de ensino secundário estudadas nas teses e dissertações, quer fossem particulares, quer municipais, estaduais ou federais, eram obrigadas a se adaptar à legislação de âmbito nacional para conseguir autorização, concluiu-se que a legislação seria uma das primeiras fontes para escrever a história desse nível de ensino.

Para isso, foram coletados dados da legislação sobre ensino secundário em obras consideradas clássicas ${ }^{55}$ e no site da Câmara dos Deputados (Legislação), Portal de Legislação do Senado Federal, JusBrasil Legislação e Rede de Informação Jurídica e Legislativa (LexML) Brasil. Posteriormente, foram recuperadas as cópias das legislações no JusBrasil Diários - Diário Oficial da União e no Portal da Câmara dos Deputados (Legislação). Os atos oficiais não disponíveis foram transcritos. Como resultado, foi construída uma lista praticamente completa com 923 dispositivos legais de 1837 a 1971 emitidos pelo Governo central e federal, com as legislações originais, trabalho publicado com o título de Repositório da Legislação do Ensino Secundário (PESSANHA; ASSIS, 2015).

Consultando esses trabalhos foi possível mapear uma grande variedade de fontes necessárias para a escrita da história do ensino secundário no País: Fontes Documentais: correspondências (ofícios e requerimentos), matrículas e frequências de alunos, folhas de pagamento de professores, listagens e pastas individuais de alunos; Arqueológicas: artefatos; Impressas: jornais e revistas; Iconográficas: fotografias; Orais: entrevistas com ex-alunos, antigos diretores e professores; Biográficas: artigos de cunho biográfico; entre outras.

\footnotetext{
${ }^{5}$ Bicudo (1942), Brasil (1952, 1969), Dodsworth (1968), Faria e Cintra (1952), Fávero (1996), Forjaz (1906), Haidar (1972), Nagle (1974), Niskier (1989), Romanelli (1978), Saviani (2007), Souza (2008), Vechia e Cavazotti (2003), Vieira (1955) e Zotti (2004).
} 
Além da tipologia das fontes, tornou-se importante recuperar os relatos das expedições aos acervos e arquivos não apenas para que se possa avaliar a dimensão desse primeiro trabalho de separar, de reunir, de transformar em documentos certos objetos distribuídos de outra maneira (CERTEAU, 2010, p. 81), mas para tornar conhecidos os percalços de pesquisas em acervos quase nunca organizados ou de fácil acesso.

As informações sobre o caminho para as fontes para a escrita da história do ensino secundário no Brasil no período especificado foram organizadas por trabalhos, e estão apresentadas por ordem cronológica de publicação.

França (1997), em seu trabalho sobre a implantação do Liceu Paraense, em 1841, em Belém, tomou documentos oficiais como Relatórios dos Presidentes de Província e Relatórios de Diretores da Instrução Pública. Constituído por dois cursos, um de Humanidades, com duração de cinco anos, e outro de Comércio, de dois anos, foi criado o Liceu Paraense, pela Lei n. 97, de 28 de junho de 1841, que regulamentou não somente a instrução secundária como também a primária. O conjunto de leis foi consultado na Coleção das Leis da Província do Grão-Pará, disponível no Arquivo Público do Estado do Pará. Os "Relatórios apresentados à Assembléa (sic) Legislativa Provincial do Grão-Pará”, presentes no livro Typografia de Santos e Filhos, de 1851, e as "Falas dos Presidentes da Província do Grão-Pará", igualmente editadas pela Typografia de Santos e Filhos, encontram-se no Arquivo Público do Estado do Pará e no acervo do Conselho Estadual de Cultura do Pará.

Na pesquisa de Pires (1997) sobre escolas secundárias nas décadas de 1950 e 1960, em Jataí, Goiás, evidenciou-se o momento em que houve uma evidente expansão do ensino secundário na Cidade, com a abertura de uma escola católica, uma evangélica, ambas privadas, e uma pública gratuita cooperativa. A consulta a jornais permitiu averiguar que, entre 1912 e 1933, três instituições de ensino secundário abriram as portas, contrariando uma informação corrente na cidade, de que a primeira escola secundária tinha sido o Colégio Nossa Senhora do Bom Conselho. Ex-alunos foram entrevistados com o intuito de obter o paradeiro dessas três instituições e se descobriu que as escolas tiveram pouco tempo de funcionamento. Para ter acesso a dados gerais sobre o Município de Jataí, como economia, educação e religião, a autora consultou dados do IBGE e utilizou a Revista Brasileira de Estudos Pedagógicos. No Museu Histórico de Jataí, Francisco Honório de Campos, foram consultados livros e jornais editados a partir da década de 1910 .

Gentilini (2001), com o objetivo de reconstruir a história e a memória do Colégio Municipal de Belo Horizonte, de sua criação, em 1948, até 1972, realizou 
um exercício de cruzamento de fontes impressas como livros, monografias, teses, leis e decretos, artigos sobre ensino secundário na década de 1950, relatórios de prefeitos de 1947 a 1972, jornais e revistas e fontes orais que foram relatos dos sujeitos que vivenciaram o processo de constituição do Colégio Municipal. O procedimento metodológico para reunir os relatos orais foi realizado durante um ano, a partir de identificação e seleção dos entrevistados. Ao total, realizaram-se 25 entrevistas, com duração de até duas horas de depoimento. Foi traçado um roteiro, mas as entrevistas foram conduzidas de forma livre.

Cabral (2002) investigou as práticas escolares do Primeiro Gymnasio da Capital, entre 1894 e 1917, em São Paulo, SP. A pesquisadora utilizou para a pesquisa documentos do Arquivo da Escola Estadual São Paulo como fichas individuais dos alunos, livros de matrícula, provas de exames de admissão, certificados do ensino preliminar, provas, atas da congregação, atestados de vacinação e sanidade. No Arquivo do Estado de São Paulo foram pesquisados a Coleção de Leis e Decretos do Estado de São Paulo, artigos dos jornais A Província de S. Paulo, O Estado de S. Paulo e o Correio Paulistano, o Regulamento da Instrução Pública de 1892 e o Regulamento do Primeiro Gymnasio da Capital de 1895.

A história do Ginásio da Bahia, em Salvador, foi escrita por Lima (2003), que delimitou o período de pesquisa desde sua abertura, em 1895, até 1942. Para isso, a autora pesquisou os acervos do Arquivo Público do Estado da Bahia, da Biblioteca Pública do Estado da Bahia, do Colégio Estadual da Bahia, da Fundação Clemente Mariani e do Instituto Histórico Geográfico da Bahia. Dessa busca foram transformados em fontes: regulamentos, relatórios anuais, processos disciplinares, folhas de pagamento, listagens e pastas individuais dos alunos, teses de concurso para professores, memórias do educandário, artigos de cunho biográfico, fotografias, entrevistas com ex-alunos e jornais. Documento como o Horário de aulas, de 1900, traz informações sobre disciplinas e conteúdos programáticos; nos Jornais A tarde e Correio de notícias, a pesquisadora localizou o "Horário para o curso do bacharelado durante o anno de 1900 do Gymnasio da Bahia.” (LIMA, 2003). A partir dele, conseguiu entender mecanismos organizacionais da instituição e valores atribuídos a cada disciplina curricular, enquanto entrevistas demonstraram que, de alguma forma, o Ginásio da Bahia não era uma escola exclusiva de camadas altas. Buscando traçar o perfil dos alunos, foi analisado um conjunto de 281 pastas contendo registros sobre discentes do Ginásio.

Sousa (2005) buscou entender o papel social do Ginásio Manoel Borba, entre 1947 e 1974, instituição particular de ensino secundário situada em Goiana, PE. Resgatou a implantação, a organização e o funcionamento do Ginásio utilizando- 
-se da legislação sobre o ensino secundário, imprensa local e da capital do Estado, entrevistas de ex-alunos e ex-professores, documentos oficiais, correspondências e fotografias. Consultou acervos da Biblioteca Pública Municipal de Goiana e da Faculdade de Formação de Professores, que funciona hoje no antigo prédio do Ginásio Manoel Borba, e neles foram encontrados trabalhos escolares e monografias. Em relação às entrevistas, a autora informa que traçou histórias de vida a partir de entrevista semiestruturada por supor que os atores dariam informações valiosas. Tomando os fragmentos de memória, analisou o vivido conforme foi lembrado, sobre suas origens, percurso de vida escolar e profissional, bem como a relação entre os sujeitos, a cidade e a escola.

Barros (2006) pesquisou a organização do Lyceu de Goyaz, entre 1906 e 1937, enfatizando as transformações por que passou essa instituição, relacionadas à política do Estado. A pesquisadora serviu-se de documentos oficiais da instituição e do Estado de Goiás, como diários oficiais, bem como da imprensa regional. Foram visitados e consultados acervos de quatro arquivos, a saber: o Arquivo Histórico Estadual, em Goiânia, onde estão os diários oficiais do Estado e os jornais Folha de Goyaz e O Popular; o Gabinete Literário, em Cidade de Goiás, que guarda obras históricas sobre o estado de Goiás, e os Jornais A razão e O Goyaz - Órgão Democrata; o Centro de Referência Histórico das Escolas da Cidade de Goiás, mantido pela Secretaria de Educação e Cultura do Estado, onde estão armazenados documentos da instituição escolar Lyceu de Goyaz, como dossiês de alunos com histórico e registros de nascimentos, livros administrativos, como termos de exames, registros de matrícula, atas de reuniões, atas de exames finais, ofícios, termos de visitas de inspetores, boletins de notas de alunos, diários de classe, livro-caixa, folha de pagamento de docentes; e o Museu da Imagem e Som onde foram encontradas fotografias do Estado de Goiás.

Atendo-se ao processo de democratização do ensino ocorrido no Brasil, entre 1957 e 1975, que modificou e transformou a cultura escolar, Perez (2006) debruçou-se sobre a história da Escola Estadual Bento de Abreu, em Araraquara, SP. A autora visitou os arquivos da Diretoria de Ensino de Araraquara e das escolas da rede pública de ensino e explicou que esses arquivos públicos se apresentaram problemáticos quanto à localização e à conservação de seus acervos, o que acarretou perdas e mesmo a destruição de documentos mal conservados. Apesar desse revés, o fato de Perez ser funcionária da rede estadual colaborou para sua livre circulação dentro dos acervos e arquivos escolares. A pesquisadora consultou monografias, álbuns e alguns jornais da Cidade. Buscou dados estatísticos de expansão do ensino ginasial da cidade nos Recenseamentos Gerais do Brasil e do Estado de São Paulo e utilizou-se, ainda, 
da Coleção de Leis e Decretos do Estado de São Paulo. Como principal fonte de dados, tomou os mapas de movimento dos estabelecimentos de ensino pesquisados que permitiram observar o momento em que ocorreu o aumento da clientela escolar, prontuários de alunos e professores, atas de reuniões e atas de resultados finais.

Vasconcelos (2007) realizou sua pesquisa com o objetivo de apresentar aspectos da história e da memória do Liceu Piauiense, no período de 1845 a 1970, em Teresina, PI. O autor utilizou fontes documentais e iconográficas, como fotografias obtidas no Arquivo Público do Piauí, atas, decretos, relatórios de presidentes da província, resoluções, leis, no arquivo do próprio Liceu Piauiense, nas bibliotecas públicas e particulares. Relatando a dificuldade de se encontrar documentos para a pesquisa mesmo no Arquivo Público, Vasconcelos (2007) achou necessária a utilização de fontes orais. Dessa forma, aplicou entrevistas semiestruturadas com ex-alunos, ex-professores e ex-funcionários, com base na história oral como metodologia.

O Ginásio Salesiano Itajaí, em Itajaí, SC, constituiu objeto de estudo de Nicolau (2010). A autora procurou analisar e problematizar a instalação da instituição católica para meninos, as relações estabelecidas com as demais instituições sociais e as descontinuidades instauradas no processo de estabelecimento desse ginásio. $\mathrm{O}$ exercício metodológico teve como objetivo analisar fontes documentais para identificação das práticas constitutivas do processo que engendrou o ensino secundário no Brasil. O caminho traçado para buscar as fontes esteve diretamente relacionado à trajetória de formação da própria pesquisadora que estudou no colégio, assim como seu pai, de modo que as cadernetas contendo regras, penalidades, anotações, horários, notas, proposições morais que lhe foram emprestadas pelo pai facilitou o acesso aos documentos. Do acervo foram transformados em fontes: relatórios, jornais, anuários, atas, crônicas, estatuto/regimento interno, projetos-lei.

Dourado (2010) investigou a educação no antigo Norte goiano, atual Estado de Tocantins, por meio da trajetória histórica do Ginásio Estadual de Porto Nacional. Apoiada nas memórias individuais e coletivas publicadas em uma obra editada na região, a pesquisadora problematiza esse tipo de fonte e afirma não questionar a confiabilidade do teor narrativo, pois para ela não há neutralidade na abordagem do passado. Foram pesquisados os acervos do Instituto Histórico de Goiás e do Instituto de Pesquisas e Estudos Históricos-Brasil Central, em Goiânia, e, em Porto Nacional, os arquivos do Ginásio Estadual de Porto Nacional, do Colégio Sagrado Coração de Jesus, da Diocese de Porto Nacional, da Câmara Municipal de Porto Nacional e da Secretaria Municipal de Educação de Porto Nacional. A autora afirma que as fontes lhe trouxeram a memória de uma composição particular e significados atribuídos à 
experiência e sentimentos que cada sujeito viveu dentro do grupo. No Arquivo Histórico do Estado de Goiás, em Goiânia, foram encontradas as caixas dos municípios do Tocantins compostas por mapas de matrículas e frequência dos alunos, bem como termos de exames, termos de posse dos professores, relatórios e ofícios dos inspetores de ensino e da Câmara Municipal da Cidade.

Rodrigues (2010) teve como objetivo compreender a fundação do Colégio de Pedro Segundo, situado na Corte, no Rio de Janeiro, entre 1838 e 1854, em sua característica de colégio interno. Pesquisando no Núcleo de Documentação do Colégio Pedro II, o pesquisador trabalhou com fontes impressas e manuscritas. Em relação às fontes impressas utilizou decretos e leis sobre a instrução pública, relatórios da Secretaria de Estado dos Negócios do Império apresentados anualmente pelo ministro do Império na Câmara dos Deputados, nos quais foi possível obter mapas do movimento de matrículas dos alunos, bacharéis formados, aprovados e reprovados nos exames. Foram tomadas fontes manuscritas ofícios trocados entre o Colégio Pedro Segundo e a Secretaria de Estado dos Negócios do Império, ofícios recebidos, livro de matrículas n. 1, do Colégio de Pedro Segundo, livro de atas dos exames da instituição.

Com objetivo de estudar a história da disciplina Desenho no Atheneu Sergipense, entre 1905 e 1930, em Aracaju, SE, Guimarães (2012) analisou práticas e determinações legais em níveis nacional e estadual, além de identificar a disciplina em questão no discurso dos intelectuais. Guimarães (2012) realizou sua busca por fontes no Centro de Educação e Memória do Atheneu Sergipense. A autora selecionou legislação nacional e estadual, atas da congregação do Atheneu Sergipense, correspondências administrativas, publicações na imprensa, relatórios administrativos, boletins e solicitações de materiais para aulas de desenho. Guimarães (2012) localizou, ainda, imagens em forma de lâminas para as aulas de desenho. Quanto aos textos legislativos do Estado de Sergipe, foram colhidos na documentação sergipana e na hemeroteca da Biblioteca Pública Epifânio Dória, enquanto a legislação pertinente ao ensino de Desenho e de Artes a autora tomou do acervo digital do site da Câmara Federal.

Aksenen (2013) teve como objetivo compreender o significado, composição, conteúdos matemáticos e função dos exames de admissão no Ginásio Paranaense (atual Colégio Estadual do Paraná), entre 1930 e 1971, em Curitiba, PR. Ao optar pela pesquisa documental a pesquisadora ressalta a necessidade de questionar as fontes, e que a história oral foi utilizada como uma técnica, um procedimento. Foram coletados depoimentos de ex-alunos e ex-professores durante os três anos que versaram sobre os exames de admissão. Além das entrevistas, buscou documentos no Departamento Estadual de Arquivo Público, nas bibliotecas públicas do Paraná e da Pontifícia 
Universidade Católica do Paraná, no Conselho Estadual de Educação e no Centro de Memória do Colégio Estadual do Paraná. Houve a tentativa exaustiva, mas infrutífera, de encontrar exemplares de provas de exames de admissão em diferentes escolas e cidades.

Oliveira (2014) pesquisou a implantação e a organização dos cursos ginasiais no Sul de Mato Grosso, entre 1917 e 1942, mais especificamente em Corumbá e Campo Grande. O corpus documental da pesquisa foi formado por documentos impressos e digitalizados, tanto da escrita escolar quanto da legislação e mensagens de governantes estaduais. Para isso foram visitados o Arquivo Público de Mato Grosso e o Instituto Memória do Poder Legislativo, em Cuiabá, MT; a Escola Estadual Maria Leite, o Colégio Imaculada Conceição e o Colégio Salesiano Santa Teresa, em Corumbá, MS; os acervos do Colégio Salesiano Dom Bosco e do Colégio Nossa Senhora Auxiliadora e o arquivo da Escola Estadual Maria Constança Barros Machado (antigo Liceu Campograndense), em Campo Grande, MS. Desses acervos foram selecionados regimentos, relatórios mensais, relatórios de inspeção prévia e permanente, atas das provas parciais e atas de exame de admissão, relatos das visitas de inspetores, introduções dos relatórios, crônicas, atas das sessões de reuniões. Em relação aos acervos eletrônicos, mensagens de presidentes de províncias e de estados à Assembleia Legislativa de Mato Grosso foram colhidas no site do Center Research Libraries e documentos do Liceu Campograndense obtidos nos Arquivos digitalizados da Escola Estadual Maria Constança Barros Machado (PESSANHA; OLIVEIRA; ASSIS, 2011). Como documentos oficiais foi pesquisada a legislação educacional: exposição de motivos de reformas educativas, decretos e leis.

O ginásio público da capital de Mato Grosso, o Liceu Cuiabano, foi investigado por Nolasco (2015). A pesquisa observou processos de formação de consciência e de aprendizagem da cidadania dos alunos da instituição de 1926 a 1937 . A autora pesquisou nos acervos da Casa Barão de Melgaço e do Arquivo Público de Mato Grosso, em Cuiabá, MT, e identificou uma produção de jornais estudantis de secundaristas própria do associativismo cultural. Essa imprensa educacional tornou-se fonte da pesquisa para acessar o cotidiano, examinando o conteúdo dos artigos. Foram encontrados 10 jornais estudantis. Além da imprensa educacional foram selecionados documentos produzidos pela escola, como regulamentos, relatórios da diretoria à inspetoria da Instrução Pública, livros de registros de matrícula dos alunos, livros de atas da congregação do Liceu, registros de informações prestadas pela diretoria às autoridades da Instrução Pública, livros de registro de correspondências da escola, 
registros dos exames de admissão e dos alunos, livros de registros de lentes e professores, além de material avulso como ofícios e cartas.

\section{CONCLUSÃO}

Da leitura cuidadosa dos trabalhos selecionados, salta aos olhos a dificuldade para transformar documentos em fontes, tarefa que, além da indispensável definição clara dos objetos, objetivos e periodização, exige muita persistência e habilidade para acessar os acervos e arquivos.

Algumas instituições, como bibliotecas e arquivos públicos organizados e com acesso facilitado ao público como os mencionados anteriormente, ainda constituem exceção e, principalmente quando se trata de instituições escolares, apenas guardam o que consideram "arquivo morto" em que "papéis velhos", com histórias a serem contadas, são mantidos mais por inércia do que pelo reconhecimento da importância de sua preservação.

De forma geral, e os trabalhos analisados não constituem exceção, os investigadores registram as dificuldades para trabalhar com esses acervos: desde a precariedade do acondicionamento e dos próprios documentos até as barreiras impostas ao seu acesso, quando a instituição não abre as portas ao pesquisador; barreiras quebradas apenas em razão dos relacionamentos informais que atuam como facilitadores. Sem mencionar o tempo necessário para conseguir um mínimo de organização na documentação. Trabalho que, não poucas vezes precisa ser refeito a cada nova "expedição desbravadora".

A análise dos relatos das idas e vindas aos arquivos, as tentativas de superar as dificuldades de acesso, as descobertas da existência de documentos que começavam a fazer sentido no caminho da investigação e, muitas vezes, a angústia de saber que um ano ou um período inteiro de documentação tinha se perdido por problemas de má conservação, mostrou que todos viveram experiências muito próximas, e que estas precisam ser conhecidas e compartilhadas.

Como todo mapa, esse também foi feito do ponto de vista de quem o desenhou com o seu viés e os seus interesses, por isso, ao publicá-lo, espera-se que seja útil aos pesquisadores da história do ensino secundário, mas que seja também problematizado e ampliado.

Além desses, o limite estabelecido para a busca nas bases de dados com o descritor "instituições escolares de ensino secundário" restringiu a busca e pode ter 
deixado de fora algumas dissertações e teses que poderiam fornecer outros caminhos e enriquecer o trabalho.

Mesmo considerando essas limitações, podem ser propostos caminhos que indiquem pelo menos o ponto de partida para buscar fontes para escrever a história do ensino secundário.

A riqueza e a variedade de fontes utilizadas pelos pesquisadores sugerem que a escrita da história do ensino secundário não se sustenta apenas na análise da legislação que seria, por assim dizer, a voz oficial; há muitas informações na imprensa, nos arquivos públicos, nas bibliotecas públicas, nos arquivos das secretarias de educação e das instituições escolares e nas caixas de arquivos pessoais. Mesmo assim, o recurso à legislação não foi desprezado pelos pesquisadores e serviu como base para analisar tanto as políticas governamentais quanto as concepções, algumas vezes conflitantes, sobre esse nível de ensino. Além de serem citados nas obras consideradas clássicas sobre ensino secundário esses dispositivos legais podem ser consultados no site da Câmara dos Deputados (legislação), no Portal de Legislação do Senado Federal; no JusBrasil Legislação e na Rede de Informação Jurídica e Legislativa (LexML) Brasil. ${ }^{66}$ Em alguns estados foram encontradas compilações da legislação estadual sob a forma de coleções, como coleção de leis e decretos do Estado de São Paulo e a Coleção das Leis da Província do Grão-Pará.

Além da legislação, os pesquisadores recorreram aos dados estatísticos do Instituto Brasileiro de Geografia e Estatística (IBGE) e dos anuários estatísticos elaborados em alguns estados.

Mapeando as teses e dissertações selecionadas, identificamos lugares onde podem ser garimpados documentos com possibilidade de se transformar em fontes em vários estados. Merecem destaque os espaços institucionais organizados para a guarda e disponibilização de documentação com valor histórico: na Bahia, o Arquivo Público do Estado da Bahia, o Instituto Histórico Geográfico da Bahia, a Fundação Clemente Mariani, a Biblioteca Pública do Estado da Bahia, a Biblioteca Pública do Colégio Estadual da Bahia e o Departamento Estadual de Arquivo Público da Bahia; em Goiás, o Instituto Histórico de Goiás, o Arquivo Histórico do Estado de Goiás, o Instituto de Pesquisas e Estudos Históricos-Brasil Central, o Centro de Referência Histórico das Escolas da Cidade de Goiás, o Museu da Imagem e Som de Goiás e o Museu Histórico de Jataí Francisco Honório de Campos; em Mato Grosso, a Casa

\footnotetext{
${ }^{6}$ Embora não tenha sido utilizado nas teses e dissertações analisadas, pois sua publicação foi posterior, cabe registrar que o Repositório da Legislação do Ensino Secundário (PESSANHA; ASSIS, 2015) traz uma lista praticamente completa com 923 dispositivos legais de 1837 a 1971 emitidos pelo Governo central e federal, com as legislações originais.
} 
Barão de Melgaço, o Arquivo Público de Mato Grosso e o Instituto Memória do Poder Legislativo; no Pará, o Arquivo Público do Estado do Pará e o Conselho Estadual de Cultura do Pará; no Paraná, a Biblioteca Pública do Paraná e a Biblioteca da Pontifícia Universidade Católica do Paraná; em Pernambuco, a Faculdade de Formação de Professores e a Biblioteca Pública Municipal de Goiana; no Piauí, o Arquivo Público do Piauí; no Sergipe, a Hemeroteca da Biblioteca Pública Epifânio Dória; em São Paulo, o Arquivo do Estado de São Paulo e os arquivos da Diretoria de Ensino de Araraquara; e no Tocantins, a Câmara Municipal de Porto Nacional e a Secretaria Municipal de Educação de Porto Nacional.

Não menos importante é a documentação armazenada nas escolas e transformadas em fontes pelos pesquisadores. Essa documentação é produzida para atender às exigências legais e burocráticas, e sua organização e conservação dependem da vigência desses dispositivos. Quando as exigências desaparecem ou são substituídas por outras atualizadas, deixam de ser "arquivos vivos" e se transformam em "arquivos mortos" ou papéis velhos sem nenhum interesse. Mesmo assim, por alguma razão, são mantidos em algum espaço não utilizado da escola, e quando a escola sente necessidade desse espaço, são descartados ou acumulados em outro lugar ainda disponível (PESSANHA; OLIVEIRA; ASSIS, 2011).

Transformar esses papéis velhos em fontes demanda, quase sempre, um trabalho inicial de limpeza e um mínimo de organização. Alguns desses acervos, quase sempre por força do trabalho de pesquisadores de história da educação, foram organizados e constituem centros de memória como o Centro de Educação e Memória do Atheneu Sergipense; o Centro de Memória do Colégio Estadual do Paraná; o Núcleo de Documentação do Colégio Pedro II. E outros menos organizados: acervos da Escola Estadual Maria Leite, do Colégio Imaculada Conceição e do Colégio Salesiano Santa Teresa, em Corumbá, MS; do Colégio Salesiano Dom Bosco, do Colégio N. S. Auxiliadora e da Escola Estadual Maria Constança Barros Machado (antigo Liceu Campograndense), em Campo Grande, MS; arquivo do Liceu Piauiense, da Escola Estadual São Paulo; do Ginásio Estadual de Porto Nacional, do Colégio Sagrado Coração de Jesus, da Diocese de Porto Nacional em Porto Nacional, TO. Alguns com acervos digitalizados como é o caso do Liceu Sergipense em Sergipe e do Colégio Estadual Maria Constança Barros Machado em Mato Grosso do Sul.

Nesses espaços de memória, os pesquisadores localizaram e transformaram em fontes enorme variedade de documentos produzidos em várias instâncias de administração e regulação das atividades escolares: álbuns; anuários; livros de atas de congregação, de provas parciais, de sessões de reuniões; de exame de admissão, de 
exames finais, de resultados finais, dos exames da instituição; boletins de notas de alunos; cadernetas contendo regras, penalidades, anotações, horários, notas, proposições morais; artigos de jornais; correspondências administrativas; fotografias; crônicas; atestados de vacinação e sanidade; certificados; diários de classe; dossiês de alunos com histórico e registros de nascimentos; estatuto; fichas individuais dos alunos; folha de pagamento de docentes; horário de aulas; lâminas para as aulas de desenho; jornais estudantis; livro-caixa; livro de matrículas; livros administrativos, como termos de exames; livros de registro de correspondências; livros de registros de lentes e professores; mapas de matrículas e frequência dos alunos; mapas de movimento de matrículas dos alunos, bacharéis formados, aprovados e reprovados nos exames; memórias do educandário; ofícios e cartas enviados e recebidos; pastas individuais dos alunos; processos disciplinares; prontuários de alunos e professores; provas; registros de informações prestadas pela diretoria às autoridades da instrução pública; registros de matrícula; registros dos exames de admissão e dos alunos; relatórios administrativos; relatórios anuais; relatórios da diretoria à inspetoria da instrução pública; relatórios de inspeção prévia e permanente; relatos das visitas de inspetores; relatos das visitas de inspetores; termos de exames; termos de posse dos professores; termos de visitas de inspetores; teses de concurso para professores. ${ }^{77}$

Também constituíram fontes, relatórios dos presidentes de província, entrevistas com alunos e ex-alunos, professores e ex-professores, diretores e pessoal administrativo, além de obras memorialísticas.

Embora ainda não tenham sido exploradas todas as fontes, as primeiras abordagens permitiram levantar algumas hipóteses sobre como se realizou a implantação e a expansão do ensino secundário no Brasil que orientarão as próximas etapas da pesquisa.

Chama a atenção, em primeiro lugar, que grande parte das fontes identificadas nas dissertações e teses se relaciona com a história de instituições escolares vistas como marcos da história da educação das respectivas cidades pelos grupos que nela se consideravam elite ou estavam em busca de ascensão social pela escolaridade.

Colaborou para a formulação dessa hipótese o fato de que as primeiras iniciativas de criação de estabelecimentos de ensino secundário foram, em muitos casos, resultado de mobilização de grupos com força política nas capitais ou nas cidades mais importantes de cada estado e não tiveram sua origem em ações governamentais, mas de organizações particulares, religiosas em sua maior parte. Os documentos registram

\footnotetext{
${ }^{7}$ Essa extensa lista pode parecer desnecessária, principalmente porque os nomes podem ser diferentes e os conteúdos, os mesmos. Essa diversidade provavelmente reflete as alterações nas orientações administrativas de setores ou épocas diferentes.
} 
também que o poder municipal, em um segundo momento, estabelece uma parceria com esses grupos, quer na contratação de professores, quer na cessão de prédios públicos e outras formas de apoio que permitissem a manutenção desses estabelecimentos.

Como fechamento, conclui-se que as análises aqui ensaiadas indicam a necessidade, as possibilidades e alguns caminhos para escrever a história do ensino secundário no País. Para isso, torna-se necessário, em primeiro lugar, completar o mapeamento e a problematização das fontes primárias e secundárias e levantar mais hipóteses sobre como se realizou a implantação e a expansão do ensino secundário no Brasil. Hipóteses que podem levar à construção de uma teoria e uma história das políticas de atendimento às demandas de escolarização dos jovens.

\section{REFERÊNCIAS}

AKSENEN, E. Z. Os exames de admissão ao ginásio, seu significado e função na educação paranaense: análise dos conteúdos matemáticos (1930 a 1971). 2013. 145 p. Dissertação (Mestrado em Educação)-Pontifícia Universidade Católica do Paraná, Curitiba, 2013.

ALVES, C. Estudos secundários no Brasil nos séculos XIX e XX. In: PESSANHA, E. C.; GATTI JÚNIOR, D. (Org.). Tempo de cidade, lugar de escola história, ensino e cultura escolar em "escolas exemplares". Uberlândia: EDUFU, 2012. p. $87-116$.

BARROS, F. Lyceu de Goyaz: elitização endossada pelas oligarquias goianas 19061937. 2006. 166 p. Dissertação (Mestrado em Educação)-Universidade Federal de Uberlândia, Uberlândia, 2006.

BICUDO, J. C. O ensino secundário no Brasil e sua legislação: (de 1931 a 1941 inclusive). São Paulo: José Magalhães, 1942.

BRASIL. Ministério da Educação e Cultura. Secretaria-Geral. Ementário da legislação federal no Brasil: ensino e cultura (1930 a 1967): parte I. Rio de Janeiro, RJ: Serviço de Documentação, Ministério da Educação e cultura, 1969. v. 2.

BRASIL. Ministério da Educação e Saúde. Ensino secundário no Brasil: organização, legislação vigente, programas. Rio de Janeiro: Instituto Nacional de Estudos Pedagógicos, 1952.

CABRAL, M. A. S. A invenção do aluno: a implantação do Primeiro Gymnasio da Capital, em São Paulo (1894-1917). 2002. 115 p. Dissertação (Mestrado em Educação: História, Política, Sociedade)-Pontifícia Universidade Católica de São Paulo, São Paulo, 2002. 
CERTEAU, M. A escrita da história. Rio de Janeiro: Forense Universitária, 2010. DODSWORTH, H. Cem anos de ensino secundário no Brasil: (1826-1926). Rio de Janeiro, RJ: Instituto Nacional de Estudos Pedagógicos, 1968.

DOURADO, B. B. Educação no Tocantins: Ginásio Estadual de Porto Nacional. 2010. 312 p. Tese (Doutorado em Educação)-Universidade Federal de Goiás, Goiânia, 2010.

FARIA, J. V. B.; CINTRA, M. A lei orgânica do ensino secundário e sua regulamentação: (inclusive ofícios, pareceres, ordens de serviços e despachos disciplinando a matéria). São Paulo, SP: Edição "Colmeia”, 1952.

FÁVERO, O. (Org.). A educação nas constituintes brasileiras: 1823-1988. Campinas: Autores Associados, 1996.

FORJAZ, D. Do ensino e fiscalisação nos institutos de instrucção secundaria equiparados ao Gymnasio Nacional. São Paulo: Typographia Maré, Monti, 1906.

FRANÇA, M. P. S. G. S. A. Raízes históricas do ensino secundário público na Província do Grão-Pará: o Liceu Paraense 1840-1889. 1997. 165 p. Dissertação (Mestrado em Educação)-Universidade Estadual de Campinas, Campinas, 1997.

GENTILINI, S. M. Colégio Municipal de Belo Horizonte: a utopia possível (memória e história - 1948/1972). 2001. 150 p. Dissertação (Mestrado em História Social da Cultura)-Universidade Federal de Minas Gerais, Belo Horizonte, 2001.

GUIMARÃES, D. V. S. Do ponto à forma: a disciplina Desenho no Atheneu Sergipense (1905-1930). 2012. 143 p. Dissertação (Mestrado em Educação)-Universidade Federal de Sergipe, São Cristóvão, 2012.

HAIDAR, M. L. M. O ensino secundário no Império brasileiro. São Paulo: Ed. USP; Grijalbo, 1972.

LIMA, D. K. "O banquete espiritual da instrução": o Ginásio da Bahia, Salvador: 1895-1942. 2003. 174 p. Dissertação (Mestrado em Educação)-Universidade Federal da Bahia, Salvador, 2003.

NAGLE, J. Educação e sociedade na Primeira República. São Paulo: EPU; Rio de Janeiro: FENAME, 1974.

NICOLAU, F. Para o bem da juventude e para o progresso da nossa cidade: uma análise sobre a emergência e constituição do Ginásio Salesiano Itajaí (Itajaí - SC, 1945-1956). 2010. 157 p. Dissertação (Mestrado em Educação)-Universidade de São Paulo, São Paulo, 2010. 
NISKIER, A. Educação brasileira: 500 anos de história, 1500-2000. Rio de Janeiro: Melhoramentos, 1989.

NOLASCO, S. R. O fazer-se cidadão: o jornalismo estudantil nas décadas de 1920 e 1930 no Liceu Cuiabano em Mato Grosso. 2015. 434 p. Tese (Doutorado em Educação)-Universidade Federal de Mato Grosso, Cuiabá, MT, 2015.

OLIVEIRA, S. S. Implantação e organização do curso ginasial no sul de Mato Grosso: expressões de um projeto de modernização (1917-1942). 2014. 282 p. Tese (Doutorado em Educação)-Universidade Federal de Mato Grosso do Sul, Campo Grande, 2014.

PEREZ, M. I. História de uma instituição pública de ensino secundário: implicações da democratização do ensino na cultura escolar. 2006. 123 p. Dissertação (Mestrado em Educação Escolar)-Universidade Estadual Paulista "Júlio de Mesquita Filho", Araraquara, 2006.

PESSANHA; E. C.; ASSIS, W. S. Arquivos digitalizados da Escola Estadual Maria Constança Barros Machado (Campo Grande/MS). Campo Grande: W. S. Assis, 2011.

PESSANHA; E. C.; ASSIS, W. S. Repositório da legislação do ensino secundário. Campo Grande: Ed. Oeste, 2015. 1 DVD.

PESSANHA, E. C.; OLIVEIRA, S. S.; ASSIS, W. S. Muito além de "papéis velhos": fontes para história de disciplinas escolares armazenadas em um arquivo escolar. Revista Educação em Questão, Natal, v. 41, n. 27, p. 164-191, jul./dez. 2011.

PIRES, L. L. A. O ensino secundário em Jataí nas décadas de 40 e 50. 1997. 218 p. Dissertação (Mestrado em Educação Escolar)-Universidade Federal de Goiás, Goiânia, 1997.

RODRIGUES, R. P. A educação literária no Colégio de Pedro Segundo (18381854). 2010. 115 p. Dissertação (Mestrado em História)-Universidade Federal Rural do Rio de Janeiro, Seropédica, 2010.

ROMANELLI, O. O. História da educação no Brasil (1930/1973). Petrópolis: Vozes, 1978.

SAVIANI, D. Breves considerações sobre fontes para a história da educação. In: LOMBARDI, J. C.; NASCIMENTO, M. I. M. (Org.). Fontes, história e historiografia da educação. Campinas: Autores Associados, 2004. p. 3-12.

SAVIANI, D. História das idéias pedagógicas. Campinas: Autores Associados, 2007. 
SOUSA, S. G. V. O papel social do Ginásio Manuel Borba em Goiana - PE: alternativa local de ensino secundário para rapazes (1947-1961). 2005. 305 p. Dissertação (Mestrado em Educação)-Universidade Federal de Pernambuco, Recife, 2005.

SOUZA R. F. História da organização do trabalho escolar e do currículo no século XX (ensino primário e secundário no Brasil). São Paulo: Cortez, 2008.

VASCONCELOS, M. I. B. Liceu Piauiense (1845-1970): desvendando aspectos de sua história e memória. 2007. 161 p. Dissertação (Mestrado em Educação)-Universidade Federal do Piauí, Teresina, 2007.

VECHIA, A.; CAVAZOTTI, M. A. (Org.). A escola secundária: modelos e planos (Brasil, séculos XIX e XX). São Paulo: Annablume, 2003.

VIEIRA, F. A. (Org.). Lei orgânica do ensino secundário e legislação complementar. 2. ed. Rio de Janeiro: Imprensa Nacional, 1955.

ZOTTI, S. A. Sociedade, educação e currículo no Brasil: dos jesuítas aos anos de 1980. Brasília: Plano; Campinas: Autores Associados, 2004.

Recebido em: 30 de setembro de 2016

Aceito em: 16 de janeiro de 2017

Endereço para correspondência: Rua São Paulo, 526, apto. 901, 79010-050, Campo

Grande, Mato Grosso do Sul, Brasil; eurizep@uol.com.br 